\title{
THE CONDITION OF ABORTION LAW IN NORTHERN IRELAND ${ }^{1}$
}

\section{David Capper, Reader in Law, Queen's University Belfast}

Abortion law is markedly different in Northern Ireland than in the rest of the United Kingdom. The Abortion Act 1967 does not apply in this jurisdiction and the law operating here is derived from the same sources as applied in Great Britain prior to the 1967 Act. $^{2}$ What is the condition of that law as it applies in Northern Ireland today? Does it provide clear guidance to women undergoing unwanted or difficult pregnancies and to doctors charged with responsibility for providing medical assistance to them? This and other questions were considered by Kerr $\mathrm{J}$ in In the matter of an application by the Family Planning Association of Northern Ireland for judicial review. ${ }^{3}$ In this comment only the clarity of the law will be considered in any depth.

\section{The Application}

The Family Planning Association for Northern Ireland (hereafter the applicant) sought a declaration that the Minister for Health had acted unlawfully in failing to provide advice and guidance to women and physicians in Northern Ireland on the availability and provision of services for the termination of pregnancy. Underlying this application was the argument that abortion law in Northern Ireland was so unclear that the Minister was obliged to provide this guidance so that persons affected by unwanted or difficult pregnancies understood their rights. An ancillary order of mandamus was also sought to compel the Minister to issue this guidance.

\section{The Law in Northern Ireland}

Kerr J's judgment began as follows. "Abortion is legal in Northern Ireland in certain circumstances. It has been said that there is a widespread belief that abortion here is always illegal. If there is such a belief, there is no justification for it. It is wrong and after this case there is no reason why it should persist."4 What are the circumstances in which abortion is legal in Northern Ireland?

1 Many thanks are due to Rachel Rebouche of the Queen's Human Rights Centre who read and commented upon an earlier draft of this article. Her efforts have ensured considerable improvement to the article but the author remains solely responsible for any remaining errors.

2 The Abortion Act 1967 does not actually replace the pre-existing law but operates as a graft upon it.

3 [2003] NIQB 48 (judgment delivered $7^{\text {th }}$ July 2003).

4 Ibid, para 1. The applicant's director, Ms Audrey Simpson, stressed this point when interviewed on television news shortly after judgment was handed down. In truth it is the only crumb of comfort in a judgment which was otherwise a total defeat for the applicant's objectives in launching the litigation. The applicant, however, could also derive some satisfaction from Kerr J's surprising statement, made only when delivering his judgment, that he hoped that the Department would issue guidance to clinicians notwithstanding his refusal to compel it to. 
The starting point is section 58 of the Offences Against the Person Act 1861. Essentially this makes it a criminal offence for a pregnant woman or for any other person (in the present context usually clinicians) unlawfully to attempt to procure her miscarriage. That section is supplemented by section 25(1) of the Criminal Justice Act (Northern Ireland) 1945 which makes it an offence to cause the death of a child capable of being born alive before it has an existence independent of its mother. Under section 25(1) the prosecution must prove that the act causing the death of the child was "not done in good faith for the purpose only of protecting the life of the mother." Section 25(1) seems intended to deal mainly with late term abortions not taking the form of procuring a miscarriage.

The crucial questions are when procuring a miscarriage is unlawful within the meaning of section 58 and when it cannot be shown that the act alleged to violate section 25(1) was "not done in good faith for the purpose only of protecting the life of the mother." According to the seminal case of $R \mathrm{v}$ Bourne $e^{5}$ these are essentially similar and an accused person seems only to have to put in issue the question whether he or she acted to protect the life of the mother. Once that is done the prosecution must then prove, to the requisite criminal standard of proof, that the defendant did not act for this purpose, otherwise there has to be an acquittal.

Again, according to Bourne, it seems to be unnecessary to show that a clinician honestly believed that the pregnant woman would inevitably or even probably die if the pregnancy were not aborted. MacNaughten J's direction to the jury in that case contained the following elaboration upon the meaning of the words "preserving the life of the mother":-

". . . those words ought to be construed in a reasonable sense, and, if the doctor is of opinion, on reasonable grounds and with adequate knowledge, that the probable consequence of the continuance of the pregnancy will be to make the woman $a$ physical or mental wreck, the jury are quite entitled to take the view that the doctor who, under those circumstances and in that honest belief, operates, is operating for the purpose of preserving the life of the mother." 6

This approach was followed in Northern Ireland in Northern Health and Social Services Board $\mathrm{v} F$ and $G{ }^{7}$ In that case a minor was made a ward of court when she was found to be 13 weeks pregnant. Uncontradicted psychiatric and other medical evidence before the court indicated that the ward had repeatedly stated she would kill herself or the unborn child if she could not have the pregnancy terminated. Sheil J held that the law in Northern Ireland was that an abortion could be lawfully carried out where it was performed in good faith for the purpose of preserving the life or health

5 [1939] 1 KB 687.

6 Quoted at [2003] NIQB 48, para 32. (Emphasis added). In passing it might be worth observing that MacNaughten J did not direct the jury that they were obliged to acquit in those circumstances, a direction which might be expected in respect of a legal provision having the clarity usual in the criminal law.

7 [1993] NI 268. For comment on this case and the case of $A$, infra $\mathrm{n} 9$ see T. McGleenan, "Bourne Again? Abortion Law in Northern Ireland after Re $K$ and Re A" (1994) 45 NILQ 389. 
of the mother. Health included mental health and it would be lawful to carry out an abortion in the circumstances of that case. Since, notwithstanding the ruling of the court, no obstetrician could be found in Northern Ireland willing to perform the operation, Sheil $\mathbf{J}$ granted an order permitting the procedure to be carried out in England. ${ }^{8}$

The subsequent case of Northern Health and Social Services Board $\mathrm{v}$ A and others $s^{9}$ added more detail to the meaning to be attributed to the defence of "for the purpose only of preserving the life of the mother." MacDermott LJ, in granting a declaration that it would be lawful to terminate the pregnancy of a severely mentally handicapped woman of 23 years, stated that the defence does not relate solely to some life threatening situation. "Life in this context means the physical and mental health or well being of the mother and the doctor's act is lawful where the continuance of the pregnancy would adversely affect the mental or physical health of the mother." 10 His Lordship went on to say that the adverse effect had to be "real and serious" and that "it will always be a question of fact and degree whether the perceived effect of non-termination is sufficiently grave to warrant terminating the unborn child." 11 Finally it is worth mentioning that MacDermott LJ made reference to the "unsatisfactory and uncertain" state of the law. Kerr J thought this only meant that there were uncertainties in making the clinical judgment that the facts fitted the relevant legal principles, not that there were uncertainties as to those principles themselves. ${ }^{12}$ It will be argued below that there are uncertainties about each of these matters.

A final case which must be mentioned at this stage is Western Health and Social Services Board v CMB and the Official Solicitor. ${ }^{13}$ There Pringle J granted a declaration that the termination of the pregnancy of a mentally handicapped 17 year old was lawful. In the course of his judgment Pringle J stated that the words "or well being" appearing in the judgment of MacDermott LJ in $A$ added nothing to physical and mental health and could be omitted without altering the sense of the judgment. His Lordship went on to deal with two further questions relating to physical and mental health. First, he said that the problem had to be permanent or long term and that this was what MacDermott LJ had meant by "real and serious" adverse effects. Secondly, Pringle $\mathrm{J}$ indicated that the more serious the potential consequences of non-termination the less likely those consequences would have to be before abortion became justifiable. In most cases the adverse effect would need to be a probable risk but a possible risk might be sufficient if the imminent death of the mother were the risk in question.

8 Apparently there was still a perception that any obstetrician carrying out the procedure risked prosecution.

9 [1994] NIJB 1. This application was brought by the obstetrician, indicating that clinicians had acquired a little more confidence in the legality of abortion in Northern Ireland in certain circumstances.

10 Ibid.

11 Ibid.

12 [2003] NIQB 48, para 35.

13 (1995) unreported. 
From the above authorities Kerr J, on the suggestion of counsel for the respondent and with the consent of counsel for the applicant, distilled the following principles:-

- Operations in Northern Ireland for the termination of pregnancies are unlawful unless performed in good faith for the purpose of preserving the life of the mother;

- The "life" of the mother in this context has been interpreted by the courts as including her physical and mental health;

- A termination will therefore be lawful where the continuance of the pregnancy threatens the life of the mother, or would adversely affect her mental or physical health;

- The adverse effect on her mental or physical health must be a "real and serious" one, and must also be "permanent or long term";

- In most cases the risk of the adverse effect occurring would need to be a probability, but a possibility might be regarded as sufficient if the imminent death of the mother was the potentially adverse effect;

- It will always be a question of fact and degree whether the perceived effect of a non-termination is sufficiently grave to warrant terminating the pregnancy in a particular case. ${ }^{14}$

Since abortions for foetal abnormality are omitted from the above list one can only conclude that these sorts of abortions are not permitted in Northern Ireland. Exceptionally a case may be made that a woman carrying such a child could become a physical or mental wreck were she denied a termination but this would not be abortion on the ground of foetal abnormality.

The judgment in the Family Planning Association case is extremely helpful in elucidating the law in Northern Ireland more clearly than it had been before. Kerr $\mathrm{J}$ stated his belief that the legal principles were clear and that any difficulties surrounding them were confined to deciding whether the facts of a particular case can be accommodated within them. ${ }^{15}$ This, however, may be doubted. Language such as "real and serious", "permanent or long term", "probability", "possibility", and "question of fact and degree" has an inherent vagueness to it. It is difficult to imagine that doctors would feel that the question they had to address was solely one of fitting the clinical judgment to a fixed and certain legal test. In addition to the clinical judgment as to how "real and serious", "long term" or "probable" certain risks are, there is also the threshold question of how "real and serious", "long term" or "probable" the risks need to be. With illegal abortion being a crime there would be further protection in the requirement for the prosecution to prove beyond all reasonable doubt that these principles were not satisfied. ${ }^{16}$

14 [2003] NIQB 48, para 37.

15 Ibid, para 39.

16 Civil suits do not seem to present a problem. The pregnant woman is only going to sue for a "botched" abortion. Parents and persons in loco parentis would appear to lack standing and would have enormous difficulty in proving identifiable loss. 
But the ultimate decision would rest with a jury, which would probably take at least something away from the sense of security conferred by this requirement. It is likely that doctors will make applications to the High Court for declarations that abortions would be lawful in particularly difficult cases and that women will continue to make the emotionally shattering, frequently lonely, and financially costly journey to Great Britain to access services more widely available there. When the legal position in Great Britain is compared to that of Northern Ireland the difficulties with the Northern Ireland principles become even more apparent.

\section{The Law in Great Britain}

Section 1(1) of the Abortion Act 1967, as amended by the Human Fertilisation and Embryology Act 1990, provides a complete defence for a registered medical practitioner who performs an abortion where two registered medical practitioners ${ }^{17}$ in good faith make one or other of the following four clinical judgments:-

- The pregnancy has not exceeded its twenty-fourth week and continuing it would involve greater risk to the physical or mental health of the pregnant woman or any existing children of her family than terminating it (section 1(1)(a));

- Termination of the pregnancy is necessary to prevent grave permanent injury to the physical or mental health of the pregnant woman (section 1(1)(b));

- Continuance of the pregnancy would involve greater risk to the life of the pregnant woman than termination (section 1(1)(c));

- There is a substantial risk that if the child were born it would suffer from such physical or mental abnormalities as to be seriously handicapped (section 1(1)(d)).

Kerr $\mathbf{J}$ held that the substantive law on abortion in Northern Ireland approximated to sections 1(1)(b) and (c) of the 1967 Act. ${ }^{18}$ As the Abortion Act operates as a graft upon the pre-existing legal provisions there is a degree of plausibility to this. Section 1(1)(a) could be seen as the general provision on abortion accommodating all cases falling within sections 1(1)(b) and (c) save those beyond the twenty-fourth week of pregnancy. Section 1(1)(d) is a specific provision on foetal abnormality and has no parallel in Northern Ireland. However Lord Lester's argument for the applicant cannot be dismissed too easily. Pointing out that sections 1(1)(b) and (c) exist mainly to deal with late term abortions Lord Lester suggested that "grave permanent injury" may be a higher threshold than "real and serious". If so Kerr J's judgment potentially narrows the scope for legal abortions in Northern Ireland by asserting that the tests laid down in previous Northern Ireland cases are synonymous with grounds in the 1967 Act.

It is less easy to accept Kerr J's apparent belief that the exposition above shows the legal principles in Northern Ireland to be clear. His Lordship

17 The Act does not state that these have to be two different medical practitioners.

18 [2003] NIQB 48, paras 41-43. 
referred to a letter sent by the Director of the Office for National Statistics to Crispin Blunt MP in response to a parliamentary question he asked about the number of abortions performed in England and Wales on women from Northern Ireland. ${ }^{19}$ The statistics indicated that between 1993 and 1997 exactly 8,000 women ${ }^{20}$ from Northern Ireland underwent abortions in England and Wales. Of these only $4(0.05 \%)$ were performed on the grounds set out in sections 1(1)(b) and (c) of the 1967 Act. Kerr J stated that it followed from this that "the vast majority of women who travelled to England for abortions could not have had those abortions lawfully in Northern Ireland" 21 and "that only an inconsequentially small percentage of women who would be entitled to termination of pregnancy in Northern Ireland travel to England to have an abortion." 22 The first of these quoted statements is almost certainly literally true but the second is seriously disputable. The statistics quoted do not tell us how many abortions were carried out under section 1(1)(a) because they clearly fell within the wide words of that provision but only arguably fell within sections 1(1)(b) or (c). Neither do they tell us whether any of the 4 abortions affirmatively carried out under sections 1(1)(b) or (c) were late term abortions beyond the twentyfourth week of pregnancy. There remains the distinct possibility that a small but more than inconsequential number of abortions are carried out on women from Northern Ireland under section 1(1)(a) because of legal doubt as to whether they fall under section 1(1)(b) or (c). If the threshold is higher under sections 1(1)(b) and (c) than under the Northern Ireland cases prior to Family Planning Association this becomes an even greater possibility.

\section{Commentary}

The judgment is valuable because it elucidates the principles of abortion law in Northern Ireland more clearly than ever before. There is room, however, for serious dispute as to whether those principles are anything like as clear as the learned judge stated they were. Since Kerr J was of opinion that the law was clear there was no point in issuing any orders to the Department to provide more detailed guidance for the benefit of doctors. But even if the judge had been of opinion that the law was unclear it would probably have been wise to deny the applicant's request for relief. It may be doubted whether delegation of the task of producing clarifying guidance to civil servants would have been particularly productive. The Department might have issued extremely cautious guidance giving the impression that abortion was available only in very restrictive circumstances, e.g. instances of rape and incest. Had the judge given a very detailed steer to the Department this might have approximated too much to an advisory opinion. Had this steer opened up the circumstances in which abortion was available to any large extent it could also have amounted to judicial legislation. ${ }^{23}$ In the light of this it is surprising that, as reported to the author, the judge encouraged the

19 Ibid, para 42.

20 This number may not be correct if, as is widely believed, many women give false names and addresses when travelling to England to have abortions.

21 [2003] NIQB 48, para 42.

22 Ibid, para 55.

23 The decision of the United States Supreme Court in Roe v Wade (1973) 410 U.S. 113 is widely (but not exclusively) regarded as judicial legislation. 
Department to issue guidance to doctors when he delivered his judgment in open court. This encouragement does not appear in the judgment.

Although the applicant expressly disavowed any intention to change the law by instituting these proceedings it is difficult not to suspect that this was its underlying agenda. The judge may well have suspected this too because in referring to a letter written by the applicant's Director to the Minister of Health prior to the initiation of proceedings, he stated that its true nature was "a complaint that women in Northern Ireland do not have access to abortion as readily as do women in England." 24 There is plausibility in the thought that the applicant would not have been too upset had the judge pronounced the law in Northern Ireland to be a mess beyond the power of courts to clear up satisfactorily. That may have put the heat back on the legislature to come up with a clarifying statute which might serve the incidental purpose of extending the circumstances in which abortion were available. ${ }^{25}$

It is here where Kerr $\mathbf{J}$ may well have faced a considerable dilemma and where the solution he arrived at (unsatisfactory though this was) may prove to be the best realistically achievable at the present time. In abortion law it is extremely difficult to achieve clarity without also having width. Even very narrow and specific guidance is likely to give rise to fine points of interpretation and sufficient room for doubt that a risk averse medical profession may not derive much assistance from it. In contrast section 1(1)(a) of the Abortion Act 1967 provides an extremely clear test for doctors in deciding whether they can lawfully perform an abortion. In most cases they only have to ask themselves whether going ahead with the pregnancy would involve greater risk to the health of the pregnant woman than termination. Given the relatively simple nature of abortion procedures in the early stages of pregnancy it is not usually a problem answering this question and answering it in the affirmative. ${ }^{26}$ This results in a considerable number of abortions and can quite justifiably be characterised as "abortion on demand". Abortion is one of the very few social and political issues that unites political parties and churches in Northern Ireland. A relatively recent Assembly debate on abortion clearly shows how difficult it will be to achieve any kind of clear (and liberal) abortion law in this jurisdiction. ${ }^{27}$ The late Professor Sir John Smith, who engaged in a lifelong crusade for a more modern law of crimes to the person than the Offences Against the Person Act 1861, might deplore it; others might castigate it as taking refuge in a jurisprudence of doubt, ${ }^{28}$ but it is extremely difficult to see any alternative to the status quo in the current climate.

24 [2003] NIQB 48, para 12.

25 Another possibility is that the applicant was just seeking enforcement of the Department's European Convention obligation to provide its statutory health care services fairly, consistently and with due regard to the best interests of the women concerned. To the extent that this was the applicant's objective it failed because Kerr J held it was not a "victim" within the meaning of s 7 of the Human Rights Act 1998. See [2003] NIQB 48, para 66.

26 "Social circumstances" abortions, where the effect on other children the pregnant woman has, are clearly more difficult but these are not the usual types of case.

27 See <www.ni-assembly.gov.uk/record/reports/000620.htm\#2>.

28 See M. Fox and T. Murphy, "Irish abortion: Seeking refuge in a jurisprudence of doubt and delegation" (1992) 19 Journal of Law and Society 454. 